\title{
Variable determined for optimization of alternating energy on the load by the adaptive Taguchi method
}

\author{
Erol Can
}

Department of Aviation Electric Electronics, School of Civil Aviation, Erzincan Binali Yuldırım University

Corresponding Author: cn_e@hotmail.com

Submitted : 24/12/2020

Revised : :18/05/2021

Accepted : 28/06/2021

\begin{abstract}
It is important to find the optimum point in terms of energy quality in the studies for electrical energy conversions with the converter and inverter circuits. In such studies, the authors tried to find the optimum operating point by using control systems such as PID and Fuzzy Logic in closed-loop controls. When a large number of variables are involved in finding the optimum point, closed-loop control methods such as these may be insufficient to find the optimum point. Therefore, in this study, the Adaptive Taguchi Method (ATM) with the maximumminimum value is used for the estimation of variables providing the optimum point for energy quality by using it in a multilevel inverter with a double DC-DC converter. While in traditional Taguchi Methods, dependent variables predict the results by revealing their effects on independent variables, in ATM, besides the effects of the independent variables, the effects of different dependent variables on each other are also estimated. First, the system to which the ATM will be applied is introduced. Then, the principles of applying the ATM are explained. In the known Taguchi method, variable values to be found with $3^{4}=81$ trials, variables are estimated with 27 trials, while the values of two different dependent variables in the system can be found with 54 trials instead of $2 \times 3^{4}=2 \times 81$ trials. The resulting values to be estimated with the proposed ATM method are estimated with 27 trials instead of $2 \times 81$ or 54 trials. Finally, the observation results to be used for estimation are analyzed and evaluated. By trying the prediction results, it is seen that the proposed system is quite effective because the estimated result value that is $\% 3.71$ in the experiments gives a lesser distortion value than the values used for prediction.
\end{abstract}

Keywords: Optimum point; ATM; Prediction results; Fuzzy Logic.

\section{INTRODUCTION}

The use of classical experimental design methods, which require a lot of trials, to find the optimum point of the system used is not efficient in many application areas. As the number of factors affecting the system increases, the number of experiments required increases considerably. Therefore, while the costs increase, there is a waste of time, and applications are getting harder. In such cases, the application of the Taguchi Method (T.M.) will be more efficient and easy. In many situations that require decision making, T.M. can be applied successfully. Again, in energy conversion systems, it is important to estimate variable values in order to obtain suitable results. Converter and inverter circuits are very required circuits for converting electric energy in power electronics applications (Kerem, A. 
et al., 2017; Liu, Huang and Qiu, 2020; Mondal, A. et al., 2020; Szymanski et al., 2020; Kan, Ruan, 2020; Yilmaz, E.N. et al., 2018). For the applications, closed-loop control systems such as PID and Fuzzy Logic are applied in order to reach the most suitable operating point on the system (Srinivas, Themozhi, and Nagarajan, 2020; Rijanto, Nugroho, and Ghani, 2020; Reddy, Sharma, 2021, Bounab et al., 2020). So, the output current or output voltage values generated on the load are compared with the reference values, and the system is controlled according to the rule tables previously determined. Since closed-loop control is performed in these methods, it is not possible to include different variables such as the change in the amount of load within the same experimental setup. In these methods, the system includes many variables when the switching times, the current frequency generated at the load, and the operating times of the converters are added to the number of variables. Hence, closed-loop control methods may be insufficient for system decision-making methods. In this case, many experiments are required. Therefore, the Adaptive Taguchi Method (ATM) is used for the optimization of an inverter system. In general, in the Taguchi Method studies (Erbayrak, E., et al., 2020; Kavc1 2021; Kaya 2021), independent variables affect the dependent variables. When the dependent variables affected by the same independent variables affect each other, the known Taguchi Method may be insufficient, or the number of trials to be reduced for estimation increases considerably. It is an ideal method to estimate independent variables with more than one dependent variable affecting each other without increasing the number of experiments with the proposed method. In this method, the method of maximum and minimum values is used. ATM is the first time in the literature for the optimization of a power electronics system. Using the Minimum Distortion Maximum Efficiency Taguchi is a suitable solution to find the optimum point of the circuit in which passive element effects and effects of more than one variable will be investigated. Therefore, the effect and optimization of the inverter with an inverted double DC-DC converter on the load are investigated by the proposed method. Since one of the two dependent variables in this study is the rate of distortion, when the ratio of distortion to noise is examined, the traditional Taguchi Method will not be able to make a correct estimate. The application of the proposed circuit's ATM is a great innovation although the traditional Taguchi Method has been used for some applications of different electronics (Lin, 2020; Hüner, 2020; Hannan, et al., 2019; Jiang et al., 2020). In the Adaptive Taguchi Method, the decision phase consists of 3 layers. In the known Taguchi methods, the effects of independent variables on dependent variables are revealed with their $\mathrm{S} / \mathrm{N}$ and mean values; in this study, the effect of independent variables on dependent variables as well as on each other is revealed in integrity. Therefore, the Adaptive Taguchi Method is also suggested in this study. This method has a three-layer decision-making stage as shown in Figure 6. In the first two layers, as in the fuzzy logic method, max and min values are used for the optimal results of the dependent variables. In this method, the effect of switching frequency (Sf), a working ratio of converter switches (D), impedance $(\mathrm{Z})$ in the load, current, and voltage frequency (f) on the load are examined. Distortion is Y, and Efficiency is E. In the known taguchi method, four variable values to be found with $3^{4}=81$ trials, variables are estimated with 27 trials, while the values of two different dependent variables in the system can be found with 54 trials instead of $2 \times 3^{4}=2 \times 81$ trials. The resulting values to be estimated with the proposed ATM method are estimated with 27 trials instead of $2 \times 81$ or 54 trials. Also, while suggesting an optimum point about PWM widths used in fuzzy logic and other closedloop systems used for inverter and converter circuits (Zongo, 2021; Swami, Kumar, 2021), on the same experimental setup, load quantity, switching frequency, frequency of voltage generated, and key operating ratios may be insufficient to find an optimum point for many variables at the same time. In the proposed method, it makes estimates for many variables such as switching time, the current frequency at the load, the operating rate of converter switches, and load impedance. After the studies conducted, the ATM gives the best variable values affecting the system for the optimum operating point by obtaining a $3.71 \%$ of distortion rate in the experiment with the predicted variables. In this case, it shows that the Adaptive Taguchi Method is better than the known Taguchi Method and closed-loop control methods such as Fuzzy Logic and PID.

\section{SYSTEM AND VARIABLES TO OPTIMIZATION}

The general structure of a 3-phase inverter with DC-DC converter units is shown in Figure 1. The system used contains 3 double converter units. There is pulse width modulation (PWM) controlling these converters whose 
operating rates are to be predicted. There are PWMs for which switching times control the complete inverter circuit are to be estimated. Again, there are impedances (Z1, Z2, and Z3) representing the optimum loads that the system can drive.

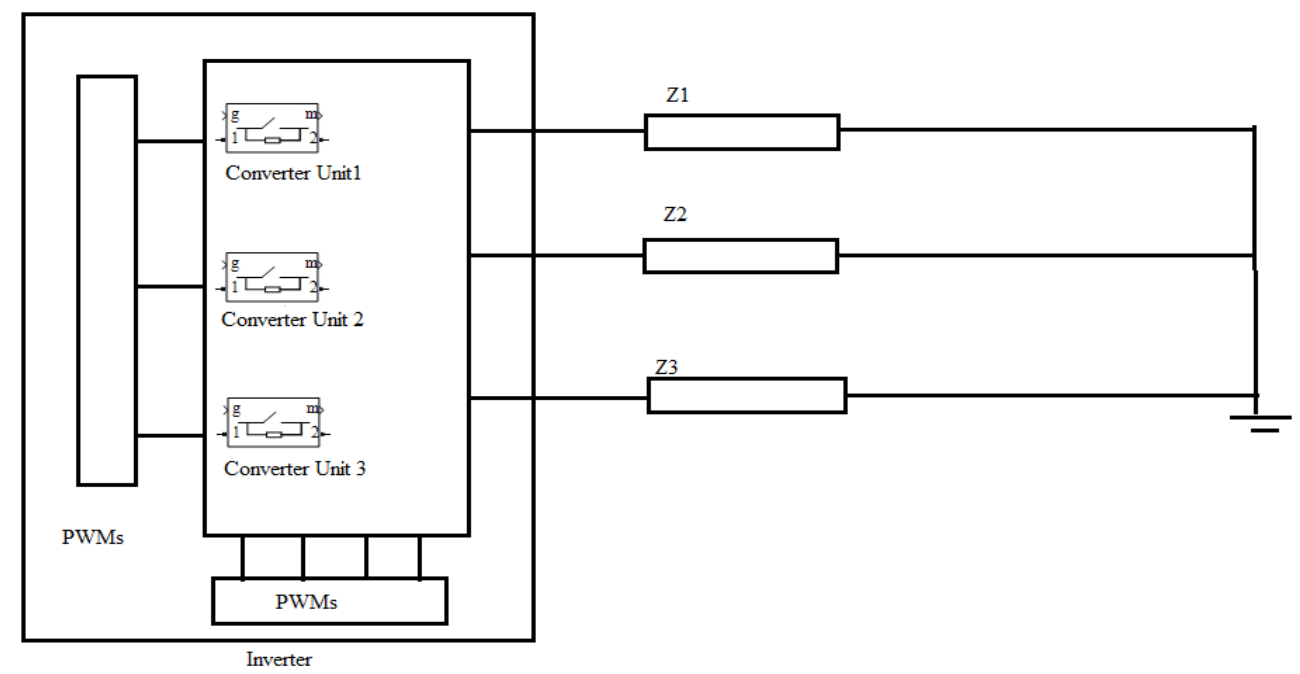

Figure 1. A 3-phase inverter with DC-DC converter units.

The logic and layout of this 3-phase inverter structure and the effect of converter structures on the system are given in a study (Can,2020). It is extremely important to find the optimum point and obtain more efficient results in such inverter studies. Although the best operating point has been tried to be achieved in closed-loop systems with control units until today (Sundaram, Romine, 2020; Srikanth, Venkatesan, and Rao, 2020; Rajeswari, Santhi, 2020), these systems remain inadequate for the different values of the load and the differences in the frequency of the current or voltage on the load. Different experimental setups and many trials should be made again for the frequency of the load current and the changing value of the load. Therefore, the Taguchi Method is a good suggestion to estimate the variables required for optimum operation when a large number of variables are involved. In this study, the two variables that affect the system are the switching frequency and the working ratio of the converter switches. The unit of switching time is seconds. These two variables affect the double 3-piece converters with inverter structure. The third variable is the frequency of the current and voltage on the load. Its unit is Hz. The variable to be considered as the fourth is the impedance $(\mathrm{Z})$ value of the load. Its unit is Ohm. The equation of the sinus current in the direction of these variables is as follows:

$I=\left[\frac{(2-D)}{(1-D)}\right] V \operatorname{Sin} \omega t \frac{1}{Z}$

In equation 1, I represents the current, and its unit is A. V represents the input voltage, and its unit is Volt. $\omega$ is the angular frequency, and the unit is $\mathrm{rad} / \mathrm{s}$. The unwanted situation that disrupts the sinus structure in the current is harmonic distortions.

The most important criterion for the nonlinear effect to cause away from the sine wave is the Total Harmonic Distortion (THD) parameter; it indicates the amount of distortion. The total harmonic distortion for current is as follows: 
$\mathrm{THD} 1=\sqrt{\frac{1}{\mathrm{I}_{1}}\left(\sum_{n=2}^{\infty} I_{n}{ }^{2}\right)}$

$I_{l}$ is the fundamental component, and $I_{n}$ represents the harmonic components. A function is $\mathrm{f}(\mathrm{t})$, but if $\mathrm{f}(\mathrm{t})=f(\mathrm{t}$ $+\mathrm{T}$ ) is satisfied, it is said to be "periodic." Such a periodic function can also be expressed in terms of the elements of a trigonometric sequence. The Fourier series of the nonlinear waveform in a generally known usage is as follows:

$\mathrm{f}(t)=A_{0}+\left(\sum_{n=1}^{\infty} A_{n} \sin n t+B_{n} \operatorname{Cos} n t\right)$

If equation 3 is regulated for simplified, the following equation is obtained:

$f(t)=A_{0}+\sum_{n=1}^{\infty} C_{n} \sin \left(n t+\varphi_{n}\right)$

The mean value component in the Fourier series is as follows:

$A_{0}=\frac{1}{2 \pi} \int_{0}^{T} \mathrm{f}(t) d t$

The coefficient $A n$ of the Fourier series can be explained as follows:

$A_{0}=\frac{2}{T} \int_{0}^{T} \mathrm{f}(t) \operatorname{Sin} n t . d t$

The coefficient $B n$ of the Fourier series can also be explained as follows:

$A_{0}=\frac{2}{T} \int_{0}^{T} \mathrm{f}(t) \operatorname{Cos} n t \cdot d t$

The effective value of the Fourier series $C n$ can be obtained as follows:

$C_{n}=\frac{\sqrt{\left(A_{n}+B_{n}\right)}}{\sqrt{2}}$

\section{DESIGN AND SYSTEM LOGIC OF THE TAGUCHI METHOD FOR ENERGY OPTIMIZATION}

\subsection{Selecting the Appropriate Orthogonal Array Energy Conversion System}

In order to reduce variation, Taguchi developed a set of statistics called signal-to-noise ratio to be used as performance criteria in experimental design. Noise Factor $(\mathrm{N})$, in order to reduce the variability arising from ordinary or system causes, is necessary to determine these reasons or factors and to select their optimal values in terms of variability. These factors that create variability are called noise factors. Taguchi divided the implementation problems into three according to the type of target and defined a different signal/noise ratio for each. The first is the smaller - better. In such problems, the target value of the quality variable (Y) is zero. $\mathrm{Y}$ is 
observation value, $\overline{\mathrm{Y}}$ is average observation value, and $\mathrm{n}$ is number of observations. In this case, the signal/noise ratio is defined as follows:

$S / N=-10 \cdot \log \left(\Sigma Y^{2} / n\right)$

The second is larger - better. In this case, the target value of $\mathrm{Y}$ is infinite, and the signal/noise ratio is defined as follows:

$S / N=-10 \cdot \log \left[\Sigma\left(1 / Y^{2}\right) / n\right]$

The third is target value - best. In such problems, a certain target value for $\mathrm{Y}$ is given. The equation is as follows:

$S / N=10 \cdot \log \left(\overline{\mathrm{Y}}^{2} / S^{2}\right)$

The Taguchi Method is the multivariate single target optimization method that will be considered for minimum target value. The equation represented by the usual minimum function using single goal optimization is as follows.

$\min S 1(w(x))=s 1((w(x 1), w(x 2) w(x 3) \ldots \ldots \ldots \ldots(x k))$

$X$ is the set of variables. $x 1, x 2, x 3 \ldots \ldots x k \in X, w$ is considered harmonic distortion value for the system.

The ordinary maximum function with multiple independent variables using multipurpose optimization is as follows:

$\max S 2(v(x))=s 2((v(x 1), v(x 2) v(x 3) \ldots \ldots \ldots . . . v(x k))$

Target functions of the real-value vector are $w$ and $v . X \rightarrow Y \in R^{k}, w(x)=(w(x 1), w(x 2) w(x 3) \ldots \ldots \ldots . . w(x k))^{T}$, $X \rightarrow Z \in R^{k}, v(x)=(v(x 1), v(x 2) v(x 3) \ldots \ldots \ldots . . . v(x k))^{T}$ where $\mathrm{v}(\mathrm{x} 1), \mathrm{v}(\mathrm{x} 2)$, and $v(x k)$ are values representing the main load current desired to maximize efficiency, respectively, $Y i$ and $Z i \in R$. The integer $\mathrm{k}$ is the function number of targets. $\quad E \rightarrow Z \in R^{k}, E(x)=(v(x 1)-w(x 1), v(x 2)-w(x 3) \ldots \ldots \ldots . . v(x k) w(x k))^{T}$, E represents efficiency and can be expressed as follows:

$\max S 3(E(x))=s 3((E(x 1), E(x 2) E(x 3) \ldots \ldots \ldots . . . E(x k))$

$\mathrm{n}$ represents the number of elements of the array. $Y i$ is the $i^{\prime}$ th element number of the array. $\mathrm{Y}$ is the number of elements in the array. The square of the difference of the i'th element from the mean is as $(Y i-\bar{Y})^{2} . \sigma$ is the standard deviation. As a result, the standard deviation is calculated as follows:

$\sigma=\sqrt{\frac{1}{n-1}\left(\sum_{i=1}^{n} Y i-\bar{Y}^{2}\right.}$

The value used in another analysis is the coefficient of variation $(\mathrm{CV})$. The Sum of Squares $\left(\mathrm{S}_{\mathrm{s}}\right)$ must be calculated to find the variance as in Eq. 16. The Sum of Squares is the sum of the squares of the differences of the variants from the mean. The variance is the sum of the squares divided by the degrees of freedom as in Eq. 17. The degree of freedom is one minus of the number of variants (n) to ensure that the calculated statistic is an unbiased estimate: 


$$
\begin{aligned}
& S_{S}=\left(\sum_{i=1}^{n} Y i-\bar{Y}\right)^{2} \\
& C V==\left(\sum_{i=1}^{n} \frac{Y i-\bar{Y})^{2}}{n-1}\right)^{2} / \bar{Y}
\end{aligned}
$$

It is used not only for a comparative assessment of the variation of the coefficient of variation in practice, but also for a characterization of the homogeneity of the population. If this indicator does not exceed $0.333 \%$ or $33.3 \%$, the trait change is considered weak, and if it is more than 0.333 , it is considered strong. When there is a strong variation, the statistical values studied are considered irregular, and the mean value is atypical, so it cannot be used as a general indicator of these values. The lower limit of the coefficient of variation is zero, and there is no upper limit. However, its value increases with increasing property change.

After the definition of all statistical values, the optimum point of the system will be found by examining the state of four variables affecting the inverter system in this study. Orthogonal arrays suitable for the problem are determined according to their degrees of freedom. In this study, the optimum point of the system will be found by examining the state of four variables affecting the inverter system: these variables are as follows: the switching time of the switches of the converters is St, the working rate of the converter switches is D, the load impedance is Z, and the frequency of the current that will occur on the load is F. After that, the degrees of freedom of each factor are one less than the factor level number. In this case, the total degrees of freedom are found in the Table 1 . The frequency views of the generated current from independent variables affecting the system are given in Figure 2. These values are $80 \mathrm{~Hz}, 100 \mathrm{~Hz}$, and $160 \mathrm{~Hz}$, respectively. Impedances of the driven loads, which are among the independent variables affecting the system, are given in Figure 2. These values are Z1, Z2, and Z3, respectively. $\mathrm{L}$ is the inductance value of the coil in units of Henry. XL is the reactance value of the coil, and its unit is ohm. The equation is calculated as in Eq. 18. Here, $\mathrm{f}$ is the frequency in unit of Hz. $\omega$ is the angular frequency, and its unit is $\mathrm{rad} / \mathrm{s} . \omega=2 \pi f \mathrm{R}$ is the ohmic value in impedance, and its unit is ohm. After that, impedance values are calculated as in equation 19. Figure 4 shows the working rates of DC-DC converters that provide multilevel voltage, one of the independent variables affecting the system. The switching time of DC-DC converters that provide the formation of multilevel voltage, one of the independent variables affecting the system, is given in Figure 5.

$$
X L=2 \pi L
$$

$$
Z=\left(R^{2}+j X L^{2}\right)^{1 / 2}
$$
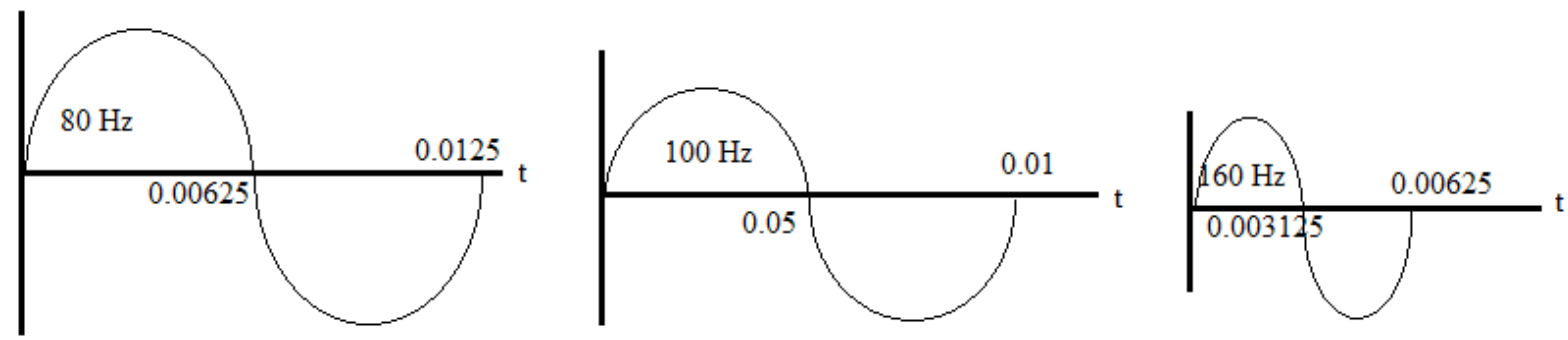

Figure 2. The frequency views of the generated current. 


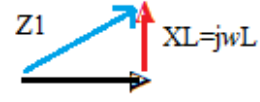

$\mathrm{R}=0.1 \mathrm{ohm}$
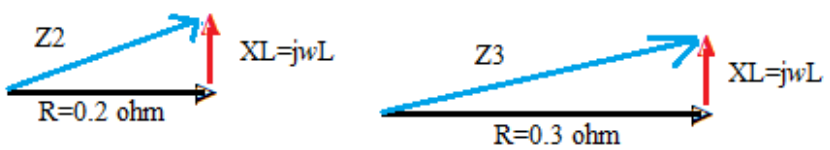

Figure 3. Impedances of the driven loads.
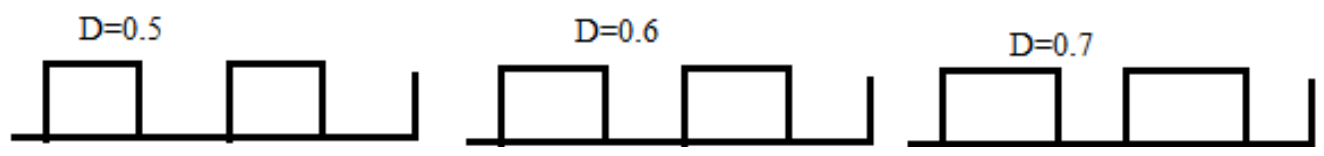

Figure 4. The working rates of DC-DC converters.
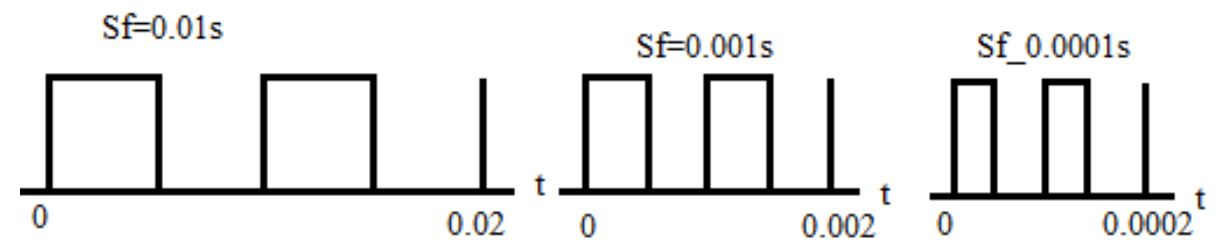

Figure 5. The switching time of DC-DC converters.

Table 1. Total degrees of freedom.

\begin{tabular}{|c|c|c|}
\hline symbol & Factor & Degrees of Freedom \\
\hline A & Frequency (F) & $3-1$ \\
\hline B & Impedance (z) & $3-1$ \\
\hline C & Switching Time (St) & $3-1$ \\
\hline D & Duty ratio (D) & $3-1$ \\
\hline & Total degrees of freedom & $2+2+2+2$ \\
\hline
\end{tabular}

The total degrees of freedom must be one less than the number of trials of the maximum chosen orthogonal array. In this case, the smallest orthogonal index L9 (34) is chosen. It is the stage of determining the experiments to be performed after determining the factors and levels to be examined during the experiments. The first data to be determined to determine the order to be selected according to the Taguchi Method is the total degrees of freedom. The degree of freedom is simply the number of comparisons that have to be made between design parameters to determine which level will work best. Since the degree of freedom is two for a three-level factor, the degrees of freedom provided by the design to be selected are the eight degrees of freedom needed for four factors. 
The nine-run Taguchi L9 experiment is one of the designs suitable for the study. The greatest degrees of freedom allowed by nine experiments is eight. The degrees of freedom other than the eight degrees of freedom required within the framework of the study are used in the calculation of the error value. The Taguchi L9 experiment design is shown in Table 2. The values in the table are the values used for the three-phase inverter circuit made in Matlab Simulink. The general scheme of this circuit is given in figure 1.

Table 2. Taguchi L9 experiment design.

\begin{tabular}{|c|c|c|c|c|c|c|c|}
\hline $\mathrm{F}$ & $\mathrm{Z}$ & $\mathrm{St}$ & $\mathrm{D}$ & $\mathrm{A}(\mathrm{F})$ & $\mathrm{B}(\mathrm{Z})$ & $\mathrm{C}(\mathrm{St})$ & $\mathrm{D}(\mathrm{D})$ \\
\hline 160 & $0.1+\mathrm{j} 0.002$ & 0.001 & 0.5 & 1 & 1 & 1 & 1 \\
\hline 160 & $0.2+\mathrm{j} 0.002$ & 0.01 & 0.6 & 1 & 2 & 2 & 2 \\
\hline 160 & $0.3+\mathrm{j} 0.002$ & 0.0001 & 0.7 & 1 & 3 & 3 & 3 \\
\hline 100 & $0.1+\mathrm{j} 0.002$ & 0.001 & 0.5 & 2 & 1 & 2 & 3 \\
\hline 100 & $0.2+\mathrm{j} 0.002$ & 0.01 & 0.6 & 2 & 2 & 3 & 1 \\
\hline 100 & $0.3+\mathrm{j} 0.002$ & 0.0001 & 0.7 & 2 & 3 & 1 & 2 \\
\hline 80 & $0.1+\mathrm{j} 0.002$ & 0.001 & 0.5 & 3 & 1 & 3 & 2 \\
\hline 80 & $0.2+\mathrm{j} 0.002$ & 0.01 & 0.6 & 3 & 2 & 1 & 3 \\
\hline 80 & $0.3+\mathrm{j} 0.002$ & 0.0001 & 0.7 & 3 & 3 & 2 & 1 \\
\hline
\end{tabular}

\subsection{Performing Tests}

In the Adaptive Taguchi Method, the decision phase consists of 3 layers. In the known Taguchi methods, the effects of independent variables on dependent variables are revealed with their S / $\mathrm{N}$ and mean values; in this study, the effect of independent variables on dependent variables as well as on each other is revealed in integrity. Therefore, the Adaptive Taguchi Method is suggested in this study. This method has a three-tier decision-making stage as shown in Figure 6. In the first two layers, as in the fuzzy logic method, max and min values are used for the optimal results of the dependent variables. After the dependent variables are analyzed in detail, their interactions with each other are revealed, and the most optimal results are selected with max and min methods. Since one of the dependent variables is total harmonic distortion, optimum values for the distortion to noise ratio would be predicted. Therefore, if the traditional TM method is applied to the distortion value, which is one of the dependent variables in the presented values, it would be difficult to obtain optimum values. Therefore, a three-layer optimization method with maximumminimum value-dependent variables as in Fuzzy logic is recommended. In this case, the proposed method allows us to find the values we also need to find in a shorter way and a correct way. In the final decision stage, the optimum results are determined by using $\mathrm{S} / \mathrm{N}$ and average values together with the max and min values. The criterion used in the method proposed to measure and evaluate the quality characteristics together with the method of max and min values at the final decision stage of the adaptive Taguchi Method is the ratio of the signal (S) to the noise factor $(\mathrm{N})$. The signal value represents the actual value given by the system and desired to be measured, and the noise factor represents the share of unwanted factors in the measured value. The quality of the quality value that is aimed to be reached as a result of the experiments in the calculation of the signal/noise ratio is also important. 
In the known Taguchi Method, $34=81$ trials are obtained with 27 observations in a system that is orthogonal, whereas, in the adjusted Taguchi method, the results to be obtained with $2 \times 82$ trials are obtained with 27 observations since the effect of independent variables on each other is examined. In this case, it is shown that the Adaptive Taguchi Method is better than the known Taguchi method.

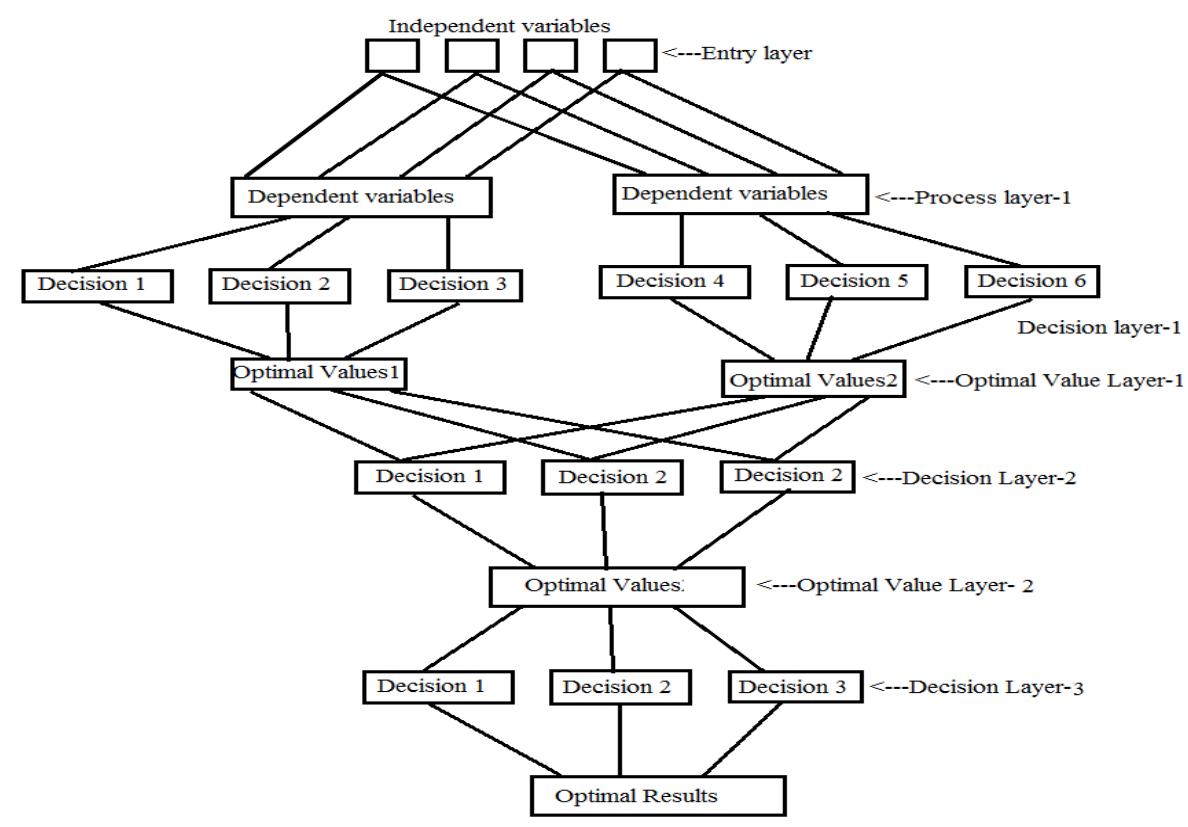

Figure 6. Adaptive Taguchi Method layers.

The distortion values of the alternating currents obtained in the applications using four independent variables are given in Table 3. For load currents transformed into 3 phases, 3 separate harmonic distortions are observed (THD). Four independent variables affect these three observed deterioration values.

Table 3. Measurement values.

\begin{tabular}{|c|c|c|c|c|c|c|c|}
\hline $\mathrm{A}$ & $\mathrm{B}$ & $\mathrm{C}$ & $\mathrm{D}$ & $\mathrm{Y} 1$ (\%THD1) & $\mathrm{Y} 2(\% \mathrm{THD} 2)$ & $\mathrm{Y} 3(\% \mathrm{THD} 3)$ & $\% \overline{\mathrm{Y}}$ \\
\hline 1 & 1 & 1 & 1 & 3,9 & 3,7 & 3,8 & 3,85 \\
\hline 1 & 2 & 2 & 2 & 4,36 & 4,42 & 4,3 & 4,36 \\
\hline 1 & 3 & 3 & 3 & 4,4 & 4,7 & 4,6 & 4,566 \\
\hline 2 & 1 & 2 & 3 & 4 & 4,2 & 3,9 & 4,033 \\
\hline 2 & 2 & 3 & 1 & 5,4 & 5,2 & 5 & 5.2 \\
\hline 2 & 3 & 1 & 2 & 4,9 & 4,8 & 5 & 4,9 \\
\hline 3 & 1 & 3 & 2 & 5, & 5,1 & 5,11 & 5,07 \\
\hline 3 & 2 & 1 & 3 & 5,9 & 5,8 & 5,4 & 5.7 \\
\hline 3 & 3 & 2 & 1 & 6.2 & 6,4 & 6,1 & 6,233 \\
\hline
\end{tabular}


$\mathrm{F}$ is the main harmonic and fundamental dependent variable. Since distortions are a noise factor, it is calculated as a percentage of the main harmonic. In calculations, when the distortion value is subtracted by taking the main harmonic value as $100 \%$, an efficiency (E) value can be obtained as in equation 20 . While $\mathrm{E}$ is calculated briefly as in equation 21, the algorithm of the optimization method is given in Figure 8. The algorithm of the traditional Taguchi Method is as given in Figure 7. If a decision is made for the ratio of distortion to noise with the TM method, it would not be difficult and correct to achieve optimum results. Therefore, as shown in Figure 8, ATM is a correct method for optimization.

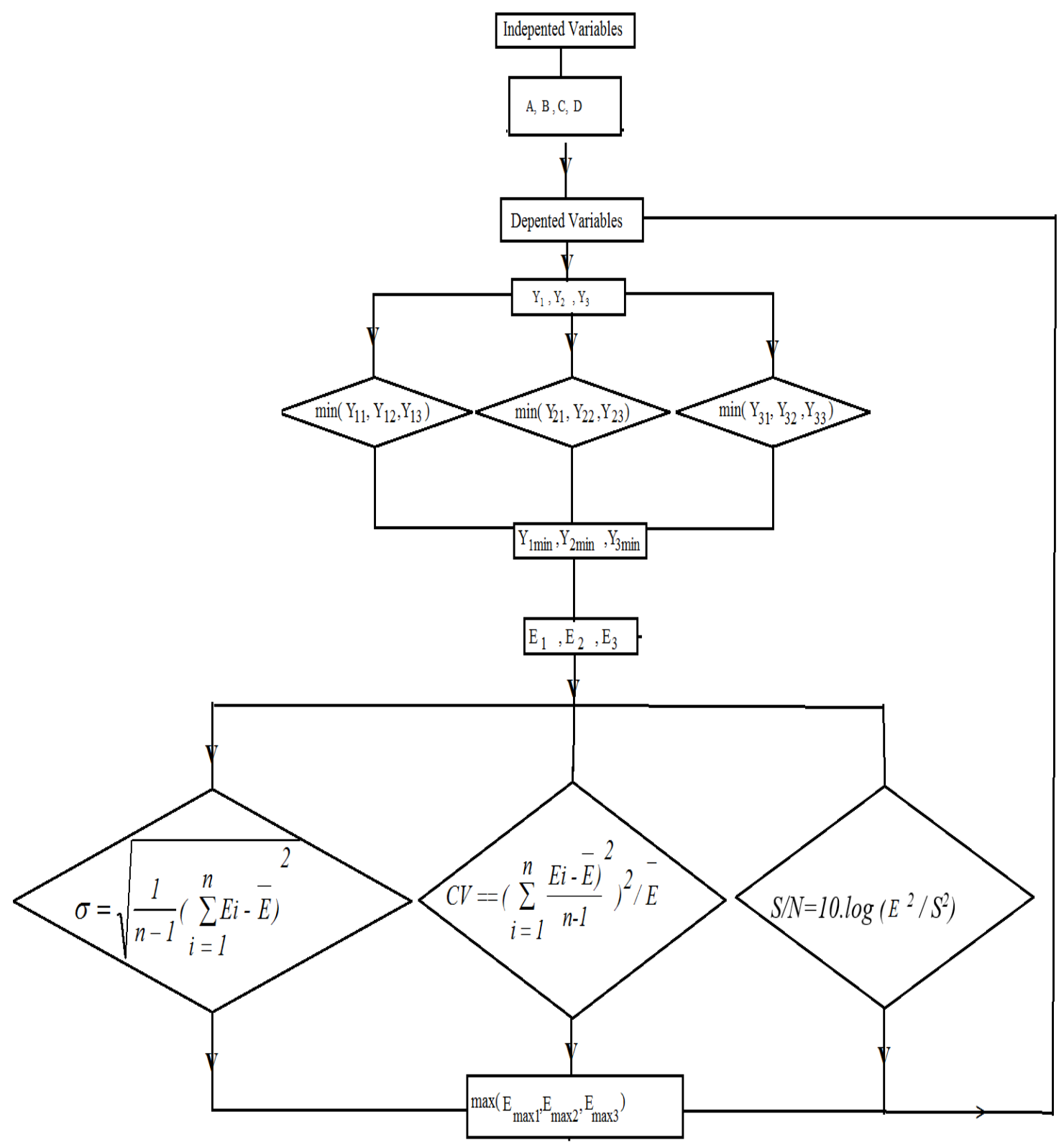

Figure 7. The algorithm of the optimization method for TM. 


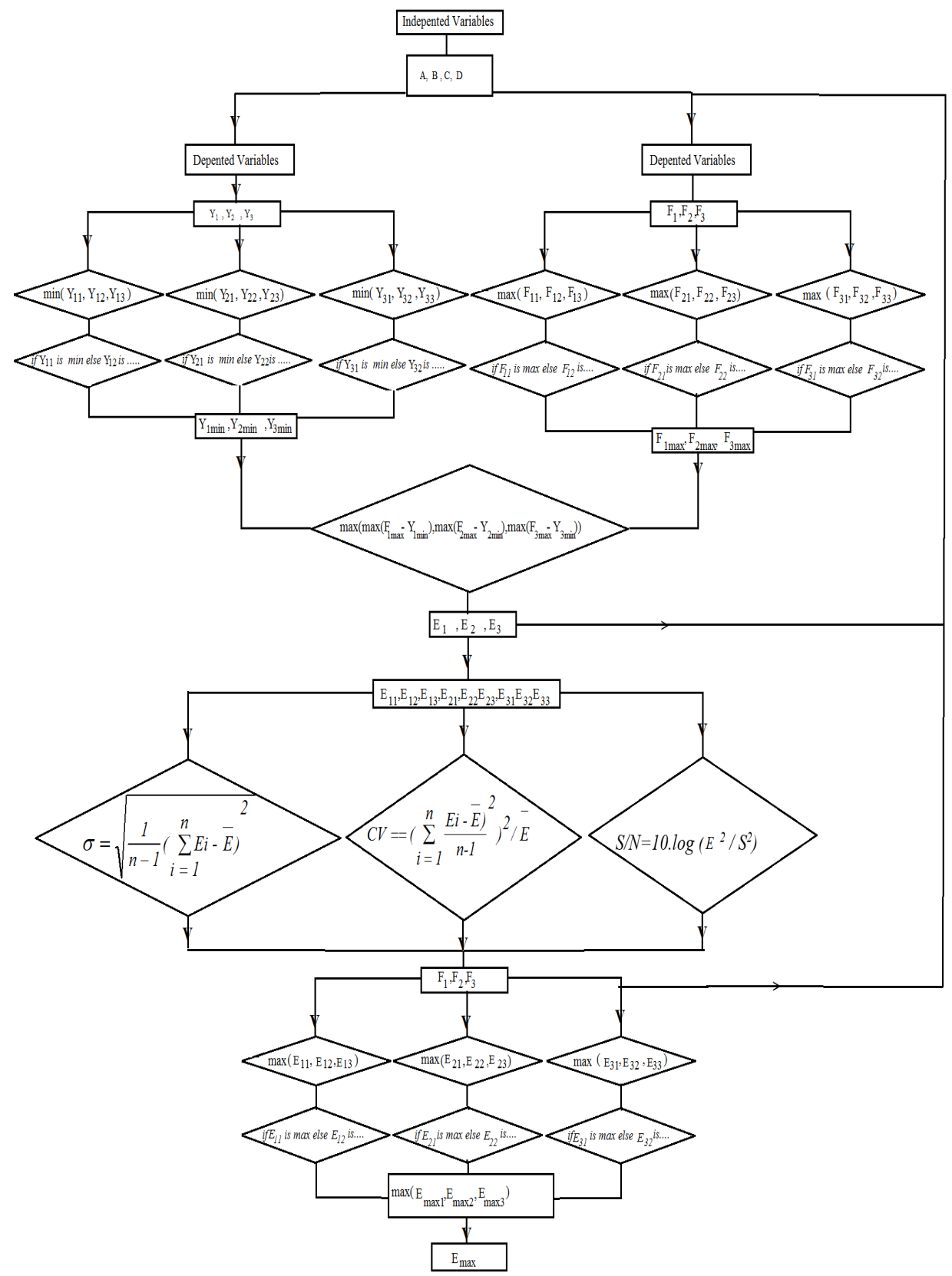

Figure 8. The algorithm of the optimization method for ATM.

$$
\left(\begin{array}{l}
\bar{E}=\% \bar{F}-\overline{\%} Y \\
E_{1}=\% F_{1}-\% Y_{1} \\
E_{2}=\% F_{2}-\overline{Y_{2}} \\
E_{3}=\% F_{3}-\overline{\%} Y_{3}
\end{array}\right)
$$


Calculations for different measurement values of each efficiency are as follows;

$$
\left(\begin{array}{l}
E_{11}=\% F_{11}-\% Y_{11} \\
E_{12}=\% F_{12}-\% Y_{12} \\
E_{13}=\% F_{13}-\% Y_{13}
\end{array}\right) ;\left(\begin{array}{l}
E_{21}=\% F_{21}-\% Y_{21} \\
E_{22}=\% F_{22}-\% Y_{22} \\
E_{23}=\% F_{23}-\% Y_{23}
\end{array}\right) ;\left(\begin{array}{l}
E_{31}=\% F_{31}-\% Y_{31} \\
E_{32}=\% F_{32}-\% Y_{32} \\
E_{33}=\% F_{33}-\% Y_{33}
\end{array}\right)
$$

The variables to be used for predictions can be rearranged as in Table 4 .

Table 4. Efficiency (E) values.

\begin{tabular}{|c|c|c|c|c|c|c|c|}
\hline $\mathrm{A}$ & $\mathrm{B}$ & $\mathrm{C}$ & $\mathrm{D}$ & $\mathrm{E} 1(\%)$ & $\mathrm{E} 2(\%)$ & $\mathrm{E} 3(\%)$ & $E(\%)$ \\
\hline 1 & 1 & 1 & 1 & 96,1 & 96,3 & 96,2 & 96,10 \\
\hline 1 & 2 & 2 & 2 & 95,7 & 95,6 & 95,7 & 95,65 \\
\hline 1 & 3 & 3 & 3 & 95,6 & 95,7 & 95,4 & 95,44 \\
\hline 2 & 1 & 2 & 3 & 96 & 95,8 & 96,1 & 95,07 \\
\hline 2 & 2 & 3 & 1 & 94,6 & 94,8 & 95 & 94,8 \\
\hline 3 & 3 & 1 & 2 & 95,1 & 95,2 & 95 & 95,2 \\
\hline 3 & 2 & 1 & 3 & 94,1 & 94,2 & 94,6 & 94,3 \\
\hline 3 & 3 & 2 & 1 & 93,8 & 93,6 & 93,9 & 93,77 \\
\hline
\end{tabular}

The values here are second-stage dependent variables. 2x81 trials are required to find the optimum conversion value for three different values of four independent variables such as inverters. With this proposed method, it is possible to predict the optimum point with 9 trials. E1, E2, and E3 are efficiencies for every pleasure. $\bar{E}(\%)$ is average efficiency. Table 5 shows the results obtained from the Minitab program. Table 6 gives the mean and $\mathrm{S} / \mathrm{N}$ ratios together with the effect values. 
Table 5. Minitab printouts of the observation values.

\begin{tabular}{|c|c|c|c|c|c|c|c|c|c|c|c|c|}
\hline A & B & C & D & E1(\%) & E2(\%) & E3(\%) & $\bar{E}(\%)$ & SNRA & LSTD & STDE & MEAN & CV \\
\hline 1 & 1 & 1 & 1 & 96,1 & 96,3 & 96,2 & 96,10 & 39,6612 & $-2,42317$ & 0,088641 & 96,1750 & 0,0009217 \\
\hline 1 & 2 & 2 & 2 & 95,7 & 95,6 & 95,7 & 95,65 & 39,6148 & $-3,03924$ & 0,047871 & 95,6625 & 0,0005004 \\
\hline 1 & 3 & 3 & 3 & 95,6 & 95,7 & 95,4 & 95,44 & 39,6032 & $-1,96696$ & 0,139881 & 95,5350 & 0,0014642 \\
\hline 2 & 1 & 2 & 3 & 96 & 95,8 & 96,1 & 95,07 & 39,6219 & $-0,76495$ & 0,465358 & 95,7425 & 0,0048605 \\
\hline 2 & 2 & 3 & 1 & 94,6 & 94,8 & 95 & 94,8 & 39,5361 & $-1,81217$ & 0,163299 & 94,8000 & 0,0017226 \\
\hline 2 & 3 & 1 & 2 & 95,1 & 95,2 & 95 & 95,2 & 39,5659 & $-2,34609$ & 0,095743 & 95,1250 & 0,0010065 \\
\hline 3 & 1 & 3 & 2 & 95 & 94,9 & 94,89 & 94,93 & 39,5481 & $-3,00244$ & 0,049666 & 94,9300 & 0,0005232 \\
\hline 3 & 2 & 1 & 3 & 94,1 & 94,2 & 94,6 & 94,3 & 39,4902 & $-1,53236$ & 0,216025 & 94,3000 & 0,0022908 \\
\hline 3 & 3 & 2 & 1 & 93,8 & 93,6 & 93,9 & 93,77 & 39,4410 & $-2,08158$ & 0,124733 & 93,7675 & 0,0013302 \\
\hline
\end{tabular}

Main Effects Plot for Means

Data Means

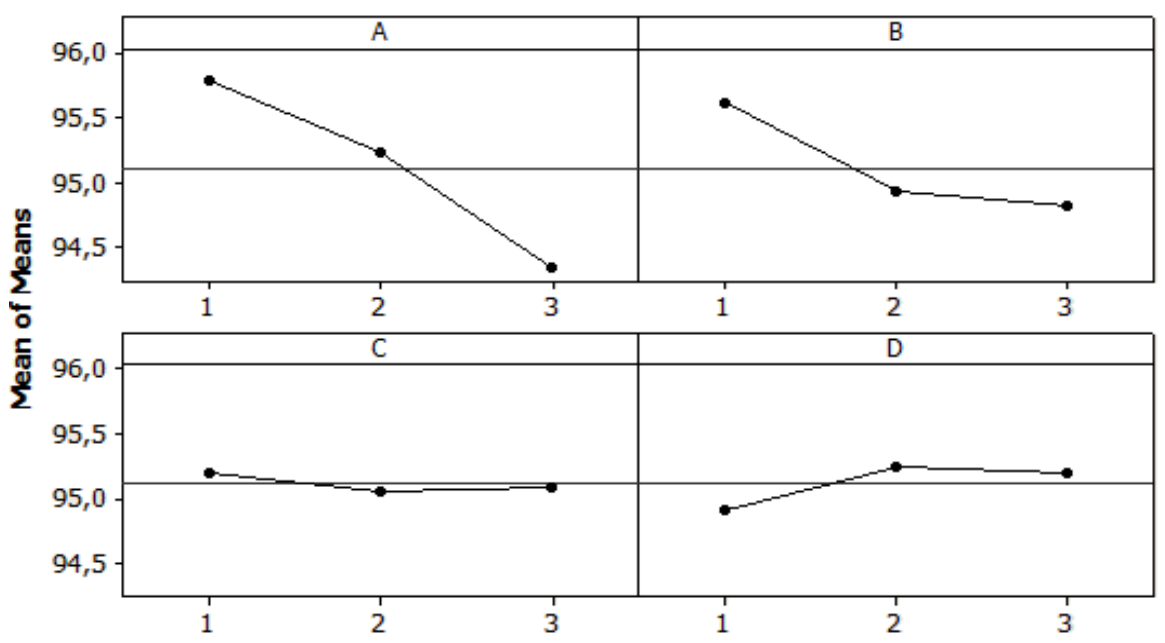

Figure 9. Result curve for means. 
Table 6. Taguchi analysis.

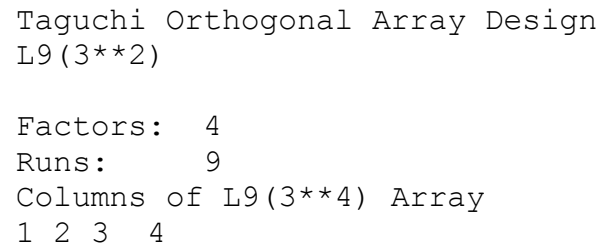

Taguchi Analysis: E1; E2; E3; Y versus A; B; C; D

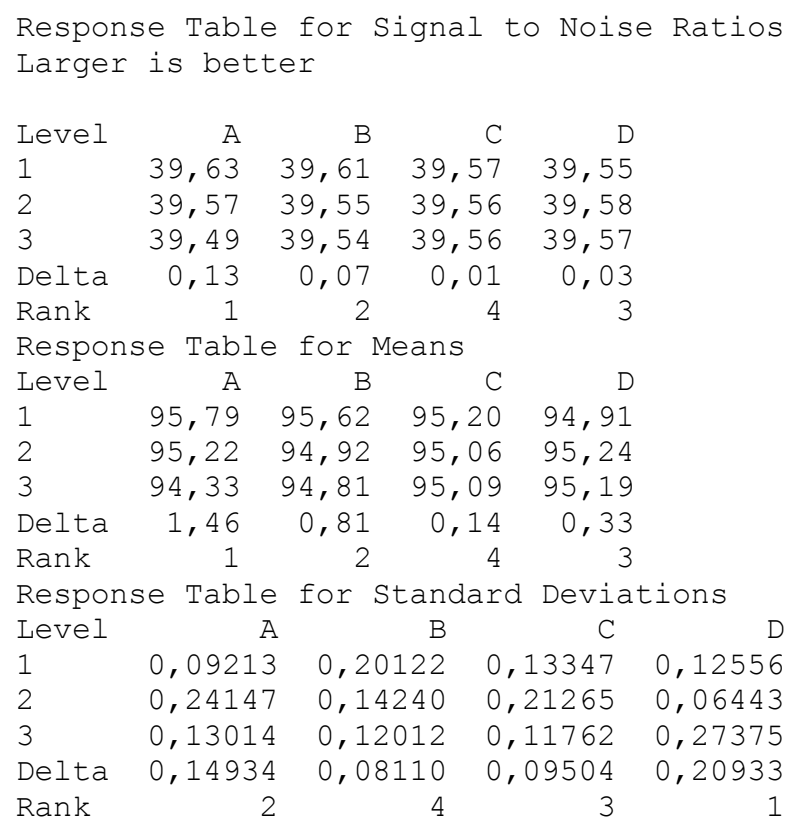

Figure 9 shows the resulting curves for the means. The frequency of the load to exert the greatest effect on the system and the impedance of the load have an effect. It is observed that the switching frequency and modulation index of converters have less effect. Figure 10 demonstrates curve of results for standard deviation, while there are results for $\mathrm{S} / \mathrm{N}$ ratio in Figure 11. 
Main Effects Plot for StDevs

Data Means

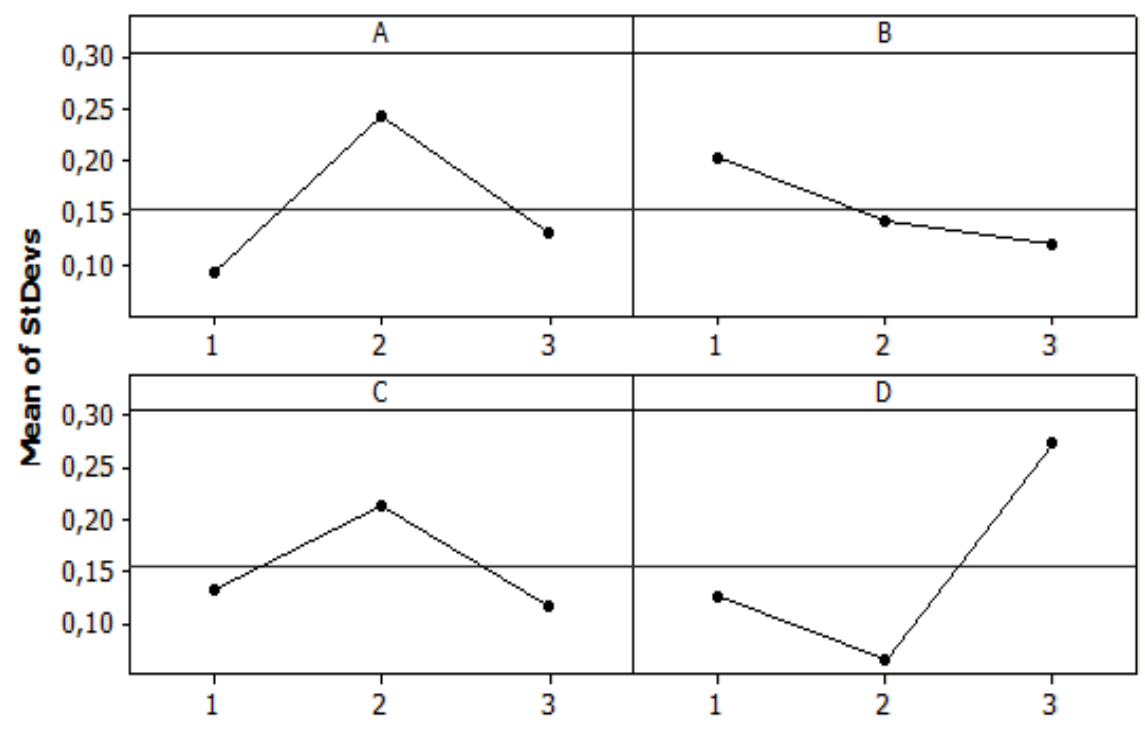

Figure 10. Curve of results for standard deviation.

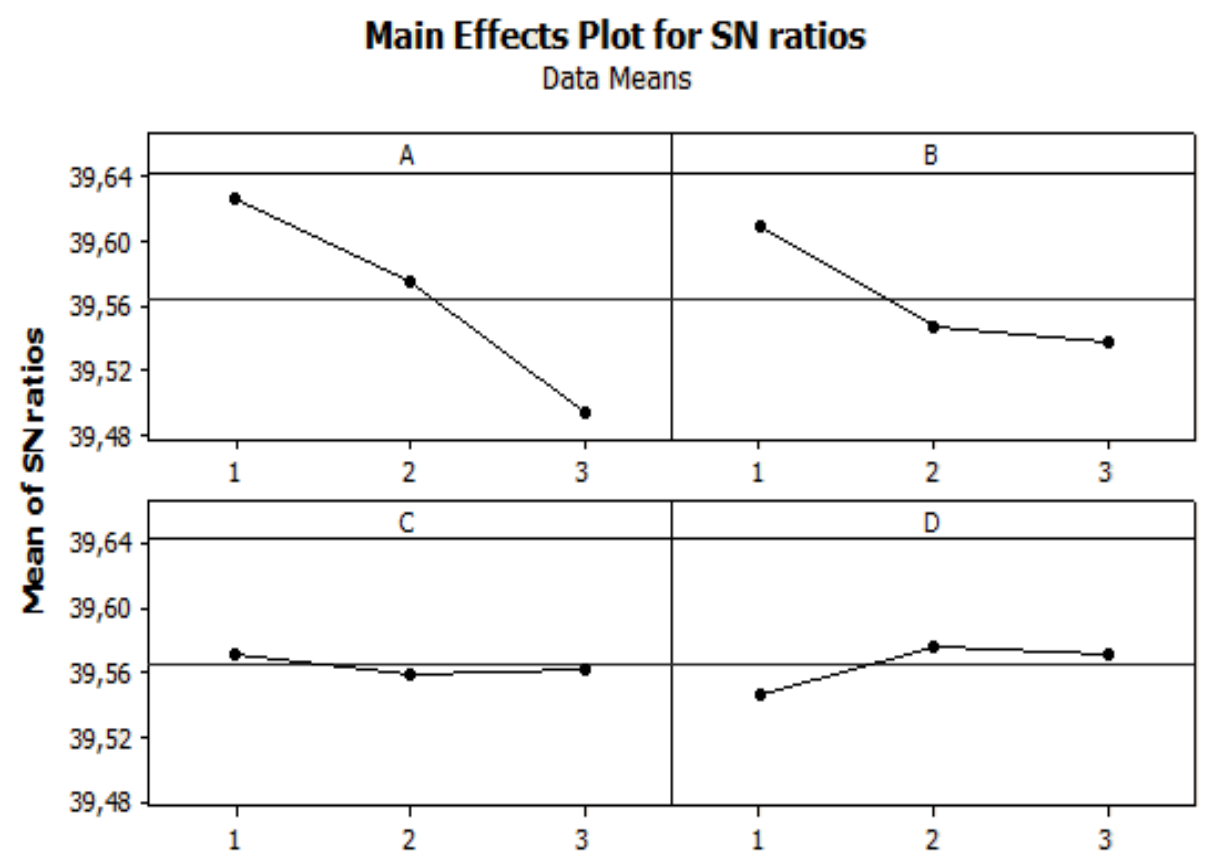

Signal-to-noise: Larger is better

Figure 11. Curve of results for $\mathrm{S} / \mathrm{N}$. 
Table 5. Data analysis summarized according to Minitab results

\begin{tabular}{|c|c|c|c|c|c|c|}
\hline & \multicolumn{2}{|c|}{ Result for S / R Ratio } & \multicolumn{2}{c|}{ Results for Means } & \multicolumn{2}{c|}{ Result for Log (Std) } \\
\hline & $\begin{array}{c}\text { Impact } \\
\text { Degree }\end{array}$ & $\begin{array}{c}\text { Suitable } \\
\text { Level }\end{array}$ & $\begin{array}{c}\text { Impact } \\
\text { Degree }\end{array}$ & $\begin{array}{c}\text { Suitable } \\
\text { Level }\end{array}$ & $\begin{array}{c}\text { Impact } \\
\text { Degree }\end{array}$ & $\begin{array}{c}\text { Suitable } \\
\text { Level }\end{array}$ \\
\hline A & 1 & 1 & 1 & 1 & 2 & 2 \\
\hline B & 2 & 1 & 2 & 1 & 1 & 2 \\
\hline C & 4 & 1 & 4 & 1 & 3 & 3 \\
\hline D & 3 & 2 & 3 & 2 & 1 & 2 \\
\hline
\end{tabular}

According to $\mathrm{S} / \mathrm{N}$ ratio, it is also seen from the curves obtained as a result of the analysis that variables $\mathrm{A}$ and $\mathrm{B}$ are highly effective on energy quality in high rate of energy conversion. The first value of the A element has the highest mean level, while the lowest level has the third value of the A element. Since the biggest value must be selected for the current, the first value of the A element is the optimum value. Therefore, the 1st element value of $\mathrm{A}$ becomes the predicted value. For C and B variables in Fig. 10, the 3rd element values are the independent variable values that will provide the optimum results, and the $3 \mathrm{rd}$ value for the $\mathrm{D}$ variable is the recommended value to provide the optimum result. Table 5 shows data analysis summarized according to Minitab results.

A summary of the values obtained as a result of the analysis in the Minitab program is given in Table 5 . Appropriate variable values according to Table 5 are given in Table 6.

Table 6. Estimated variables for optimization.

\begin{tabular}{|c|c|c|c|c|c|c|c|c|}
\hline & F & Z & St & D & A (F) & B (Z) & C (St) & D (D) \\
\hline First & 160 & $0.1+\mathrm{j} 0.002$ & 0.001 & 0.6 & 1 & 1 & 1 & 2 \\
\hline Second & 160 & $0.1+\mathrm{j} 0.002$ & 0.0001 & 0.7 & 1 & 1 & 2 & 3 \\
\hline Third & 60 & $0.1+\mathrm{j} 0.002$ & 0.01 & 0.5 & 1 & 1 & 2 & 1 \\
\hline
\end{tabular}

As the frequency $\mathrm{F}$ of the current used in the calculations increases and the ohmic $(\mathrm{R})$ value in impedance decreases, the values obtained approach to the desired level. The working ratio of the converters is 0.6 and the switching frequency (st) is brought to a medium value, which positively affects the efficiency of the system. This is clearly visible in table 6 . The system is tested again with the predicted values. Load currents and distortion values obtained in the study with estimated variable values are given in figure 12, figure 13, and figure 14. 


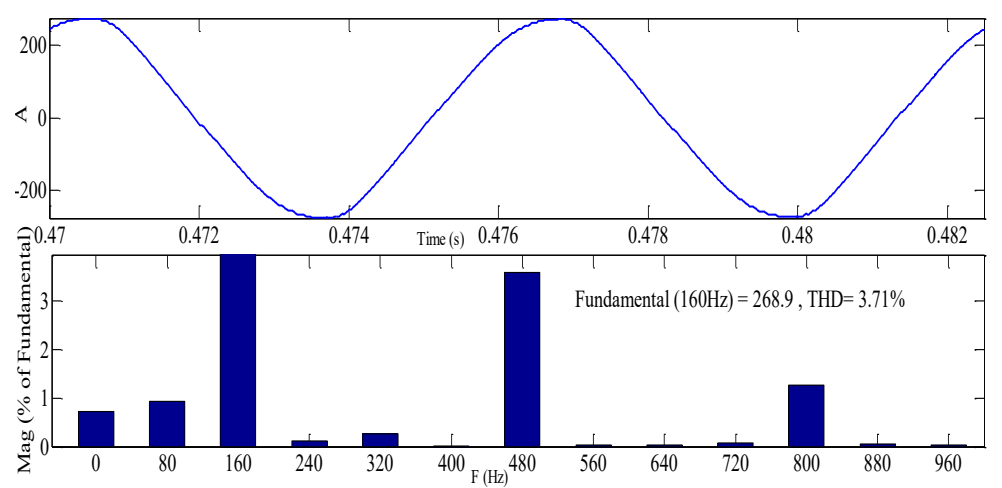

Fig. 12. First phase current and harmonic value.
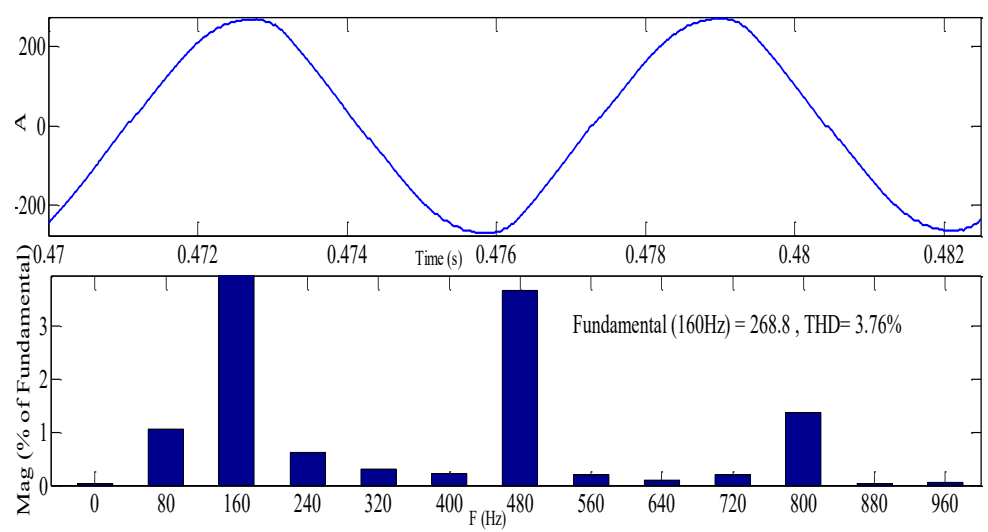

Fig. 13. Second phase current and harmonic value.

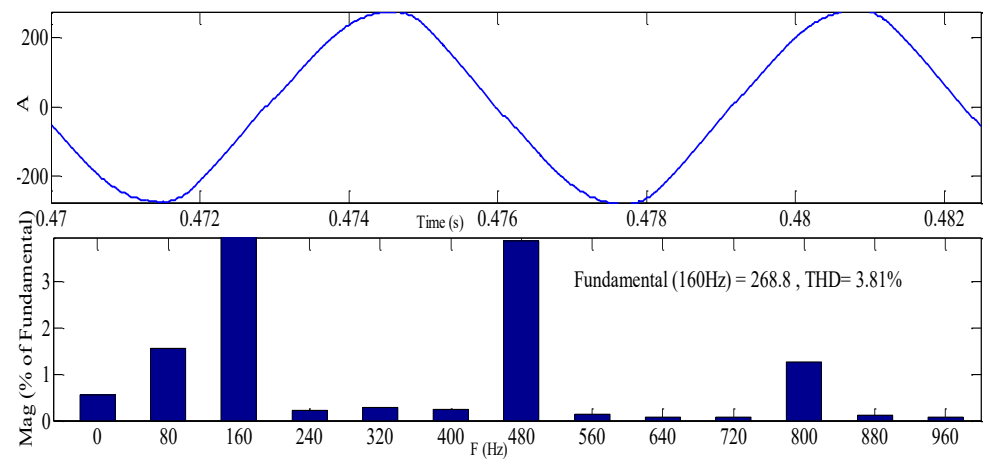

Figure 14. Third-phase current and harmonic value.

According to the estimated values of $\mathrm{A} 1, \mathrm{~B} 1, \mathrm{C} 1$, and $\mathrm{D} 2$, the inverter system is operated. Then, the current value of the first phase is 268.9 , while the THD value is $3.71 \%$. The current value of the second phase is $268.8 \mathrm{~A}$, while the THD value is $3.76 \%$. For the third phase, while the load current value is 268,8 , the THD value is 3,81 . It is seen that the data obtained in the study and the estimation results match. There are not estimated values at the experiment values. A $2 \times 81$ experiment must be done in order to receive the values of A1, B1, C1, and D2 if the optimum values of variables are taken. 


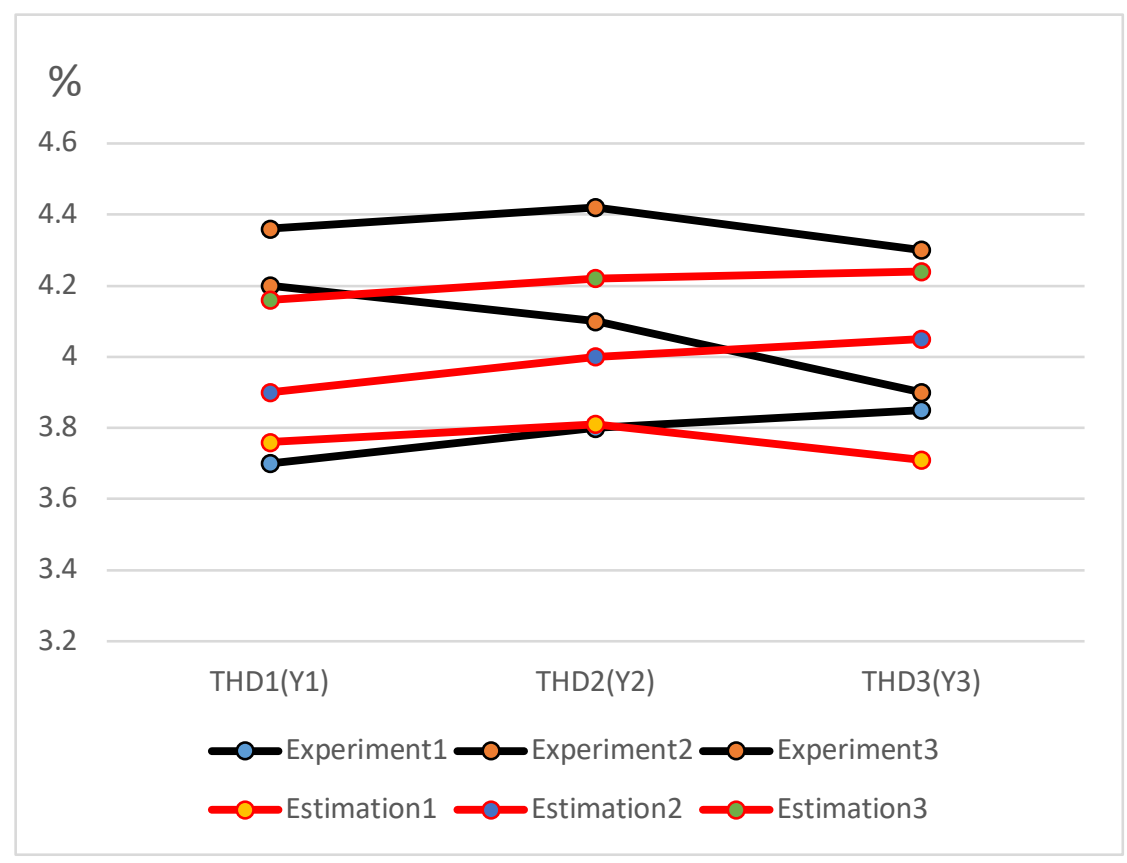

Figure 15. The least deterioration in three percent terms.

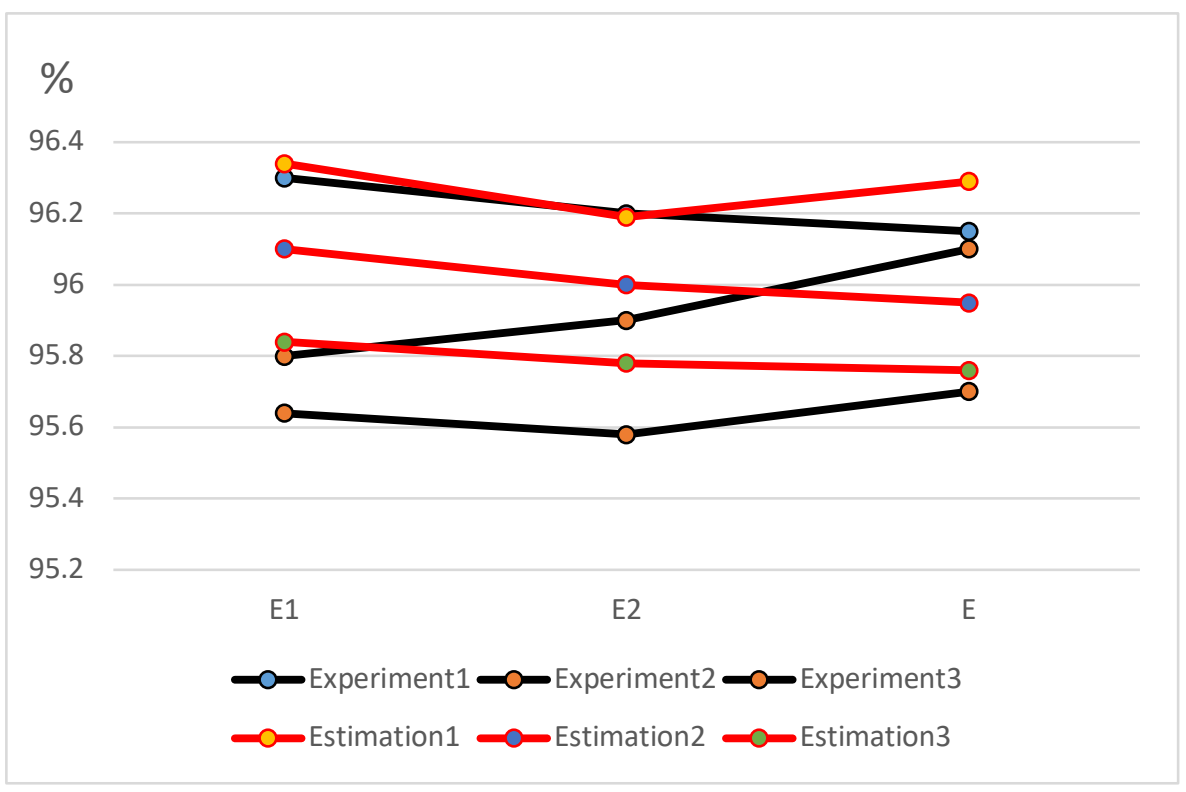

Figure 16. The highest efficiency with three observations of percentages.

Figure 15 shows the least deterioration in three observations of percent terms. These deteriorations are the percentages obtained as a result of classical experiments and by using the variables found by the proposed method. The results obtained with the proposed method, shown with red lines, are seen to be better than the best results 
obtained with black lines obtained with the traditional application. Figure 16 shows the highest efficiency with three percentages. These efficiencies are the efficiency percentages obtained as a result of classical experiments and the productivity percentages obtained by using the variables found by the proposed method. The results obtained with the proposed method, shown with red lines, are seen to be better than the best results obtained with black lines obtained as the initial values.

These values are below 4\% permitted for current in International IEEE standards. The predictive results give an effective result to the value of the variables during the conversion to alternating current. For the first time, it is shown that an inverter with a dual DC-DC converter can be effectively optimized on the load with the ATM, thus saving time and money.

\section{CONCLUSION}

One of the dependent variables in inverter circuits is the main harmonic, while the other is harmonic distortion. If optimization is attempted on harmonic distortion by applying known taguchi methods, the desired results cannot be obtained. Therefore, the adaptive Taguchi Method using the maximum values of the main harmonic with double dependent variables and the minimum point of the distortion harmonic was used. A different optimization and decision-making method is presented by demonstrating that dependent variables affect each other, and the independent variables affect each other. In the study, 9 experiments were done, and since each experiment was repeated 3 times, a total of 27 experiments were observed. Total degrees of freedom: since $\mathrm{N}-1$, the total degrees of freedom of the problem were 26 . The system was tried again with the estimation results obtained from the analysis results. While $2 \times 81$ trials are required to find the effect of four independent variables on two dependent variables with TM, it is found with 9 trials with the proposed method. According to estimated values, when the switching frequency is $0.001 \mathrm{~s}$, the least distortion occurs at $160 \mathrm{~Hz}$ of frequency and $0.1+\mathrm{j} 0.002$ of impedance. The optimum results were obtained in the experiments with the estimated values. And with the ATM, it has been shown that the optimum results can be obtained with the estimation results obtained without making many experiments.

\section{REFERENCES}

Abdulaziz, K A Y A .2021. Removal Of Crystal Violet Dye From Aqueous Solution with Pistachio Shell Powder: Optimization Of Process By Taguchi Method. Erzincan Üniversitesi Fen Bilimleri Enstitüsü Dergisi, 14(1), 357-369.

Bounab, A., Chaiba, A., \& Belkacem, S. 2020. Evaluation of the High Performance Indirect Field Oriented Controlled Dual Induction Motor Drive Fed by a Single Inverter using Type-2 Fuzzy Logic Control. Engineering, Technology \& Applied Science Research, 10(5), 6301-6308.

Can, E. 2020. A new multi-level inverter with reverse connected dual dc to dc converter at simulation. International Journal of Modelling and Simulation, 1-13.

Erbayrak, E., and S. Erbayrak. 2020. Determination of the impact damage threshold point of the composite material using fuzzy-based taguchi method." Journal of Engineering Research 8, no. 3.

Hannan, M. A., Ghani, Z. A., Hoque, M. M., Ker, P. J., Hussain, A., \& Mohamed, A. (2019). Fuzzy logic inverter controller in photovoltaic applications: Issues and recommendations. IEEE Access, 7, 24934-24955

Hüner, E. 2020. Optimization of axial flux permanent magnet generator by Taguchi experimental method. Bulletin of the Polish Academy of Sciences. Technical Sciences, 68(3).

Jiang, L., Li, Y., Huang, Y., Yu, J., Qiao, X., Wang, Y., ... \& Cao, Y. (2020). Optimization of multi-stage constant current charging pattern based on Taguchi method for Li-Ion battery. Applied Energy, 259, 114148. 
Kan, S., \& Ruan, X. 2020. Second Harmonic Current Reduction for Two-Stage Single-Phase Photovoltaic GridConnected Inverter Based on Boost Three-Level Converter. In IECON 2020 The 46th Annual Conference of the IEEE Industrial Electronics Society (pp. 1461-1465). IEEE.

Kavcı, E. 2021. Direct Red BWS tekstil boyas1 adsorpsiyonunun Taguchi L9 (34) ortogonal deney tasarımı ile araştırılması. Niğde Ömer Halisdemir Üniversitesi Mühendislik Bilimleri Dergisi, 10(1), 358-363.

Kerem, A., Aksoz, A., Saygin, A., \& Yilmaz, E. N. 2017. Smart grid integration of micro hybrid power system using 6-switched 3-level inverter. In 2017 5th International Istanbul Smart Grid and Cities Congress and Fair (ICSG) (pp. 161-165). IEEE.

Lin, C. H. (2020). Mended grey wolf optimization and Taguchi method with multi-goal optimization for six-phase copper rotor induction motor design. Engineering Optimization, 1-20.

Liu, F., Ruan, X., Huang, X., \& Qiu, Y. 2020. Second Harmonic Current Reduction for Two-Stage Inverter With DCX-LLC Resonant Converter in Front-End DC-DC Converter: Modeling and Control. IEEE Transactions on Power Electronics.

Mondal, A., Sarkar, P., \& Hazra, A. 2020. A unified approach for PI controller design in delta domain for indirect field-oriented control of induction motor drive. Journal of Engineering Research, 8(3).

Rajeswari, C., \& Santhi, M. 2020. Modified flower pollination algorithm for optimizing FOPID controller and its application with the programmable n-level inverter using fuzzy logic. Soft Computing, 1-19.

Reddy, H., \& Sharma, S.2021. Implementation of Adaptive Neuro Fuzzy Controller for Fuel Cell Based Electric Vehicles. Gazi University Journal of Science, 1-1.

Rijanto, E., Nugroho, A., \& Ghani, R. A. 2020. A robust maximum power point tracking control for PV panel using adaptive PI controller based on fuzzy logic. TELKOMNIKA, 18(6), 2999-3010.

Srikanth, R., Venkatesan, M., \& Rao, M. S. 2020. Design And Performance Evaluation Of Pid, Fuzzy And Ann Based Mppts For Hybrid Electric Vehicle Applications. International Journal of Ambient Energy, 1-29.

Srinivas, T. A., Themozhi, G., \& Nagarajan, S. 2020. Current mode controlled fuzzy logic based inter leaved cuk converter SVM inverter fed induction motor drive system. Microprocessors and Microsystems, 74, 103002 .

Sundaram, A., \& Romine, P. 2020. Design of Fuzzy-Pid with Landsman Converter (LC) Fed BLDC Drive Using IFOC Controller. In IOP Conference Series: Materials Science and Engineering (Vol. 925, No. 1, p. 012021). IOP Publishing

Swami, R. K., \& Kumar, V. 2021. DTC of Matrix Converter Fed Induction Machine Based on Fuzzy Logic. In Recent Advances in Power Electronics and Drives (pp. 517-524). Springer, Singapore.

Szymanski, J. R., Zurek-Mortka, M., Wojciechowski, D., \& Poliakov, N. 2020. Unidirectional DC/DC Converter with Voltage Inverter for Fast Charging of Electric Vehicle Batteries. Energies, 13(18), 4791.

Yilmaz, E. N., Aksoz, A., \& Saygin, A. 2018. Design of an off-grid model of micro-smart grid connection of an asynchronous motor fed with LUO converter. Electrical Engineering, 100(4), 2659-2666.

Zongo, O. A. 2021. Comparing the Performances of MPPT Techniques for DC-DC Boost Converter in a PV System. Walailak Journal of Science and Technology (WJST), 18(2), 6500-15. 